\title{
O IMPACTO DO ÁLCOOL NA MORTALIDADE EM ACIDENTES DE TRÂNSITO: UMA QUESTÃO DE SAÚDE PÚBLICA
}

The impact of alcohol abuse in mortality of traffic accidents: a matter of public health

El impacto del alcohol en la mortalidad en accidentes

de tránsito: una cuestión de salud pública

Angela Maria Mendes Abreu

José Mauro Braz de Lima

Thais de Araújo Alves

\begin{abstract}
Resumo
O estudo objetivou relacionar a mortalidade em acidentes de trânsito, no período de dezembro de 2001 a fevereiro de 2002, na cidade do Rio de Janeiro, com a taxa de álcool apresentada no sangue. Foram levantados, no Instituto Médico Legal, 267 prontuários de vitimas fatais de trânsito. Evidenciou-se a mor talidade diretamente acentuada em pessoas em idade produtiva. Observou-se que, do total, 88 vitimas (32,9\%), realizaram teste de alcoolemia, e desses 33\% foram positivos (a partir de $0,6 \mathrm{~g} / \mathrm{l}$ no sangue) e $67 \%$ apresentaram alcoolemia negativa. Ao correlacionar alcoolemia positiva com o local de óbito, observou-se que 42,2\% foram provenientes de via pública e $16,6 \%$ de hospital. Houve níveis significativos de alcoolemia em atropelamento, colisão e queda de moto. Evidenciou-se aumento de acidentes nos feriados e fins de semana. A pesquisa mostrou que $70,9 \%$ das vitimas apresentaram níveis de alcoolemia entre 1,0 e mais que 2,0g// no sangue, caracterizando 0 abuso do álcool com os acidentes de trânsito.
\end{abstract}

Palavras-chave: Teste de alcoolemia. Mortalidade. Acidentes de trânsito.

\begin{abstract}
The purpose of the study was to relate the mortality of traffic accidents to the blood-alcohol level, in Rio de Janeiro City, in Brazil, between December 2001 and February 2002. The files of 267 victims of traffic accidents were obtained from the from Medical Legal Institute in Rio de Janeiro. It was observed that the mortality was greater for people in their early productive life. Only 88 victims ( $32 \%$ of the total) were submitted to blood-alcohol testing, which revealed that $33 \%$ of them tested positive (above $0.6 \% \mathrm{~g} / \mathrm{l}$ of alcohol in the blood), and $67 \%$ tested negative. Correlating the positive results of the blood-alcohol test with the location of death, it was noted that of $42.2 \%$ died in a public street while $16.6 \%$ died in a hospital. A significant percentage of the drivers who struck pedestrians with their cars, collided with other cars, or fell from motorcycles test positive for alcohol. An increase in the number of accidents during weekends and holidays was also noticed. The research showed that $70.9 \%$ of the victims presented blood-alcohol levels between 1.0 and $2.0 \mathrm{~g} / \mathrm{l}$, which links alcohol abuse to traffic accidents.
\end{abstract}

\section{Resumen}

El studos objetivó relacionar la mortalidad de los accidentes de tránsito, en el período de diciembre de 2001 a febrero de 2002, en la ciudad de Rio de Janeiro, en Brazil, com el índice de alcohol presentado en la sangre. Fueron levantados, en el Instituto Médico Legal, 267 prontuarios de víctimas fatales de tránsito. Fue evidenciada la mortalidad directamente acentuada en personas en edad productiva. Fué observado que del total, 88 víctimas (32.9\%) hicieron prueba de alcoholemía, de los cuales $33 \%$ había sido positiva (de $0.6 \mathrm{~g} / \mathrm{l}$ en la sangre) y el $67 \%$ habían presentado alcoholemía negativa. Cuando fue correlacionado alcoholemía positiva con el lugar de la muerte, fue observado que $42.2 \%$ provinieron de via pública y $16.6 \%$ de hospital. Hubo niveles significativos de alcoholemía en atropellamientos, colisín y cáda de moto. El aumento de accidentes fue evidenciado en los días de fiesta y los fines de semana. La investigación demostró que $70.9 \%$ de las víctimas presentaron niveles de alcoholemía entre 1.0 y más que $2.0 \mathrm{~g} / \mathrm{l}$ en la sangre, caracterizando el abuso del alcohol con los accidentes de tránsito.

Palabras clave:

Test respiratorios. Mortalidad. Accidentes de tránsito.
Keywords:

Blood-alcohol. Mortality. Traffic accidents. 
INTRODUÇÃO

A violência atinge proporções alarmantes passando a ser uma questão de saúde pública extravasando os limites da segurança pública, levando-se em conta os fatores biopsicossociais, políticos e econômicos. É na área da saúde onde ocorrem as maiores conseqüências e prejuízos relacionados com o fenômeno da violência urbana, na qual se destacam os acidentes de trânsito ${ }^{1}$.

Nesse sentido, destaca-se o impacto da violência expressado através dos números elevados e crescentes, que representam indicadores negativos para o setor saúde. 0 aumento da mortalidade, principalmente em jovens, vem onerando progressivamente os gastos com os tratamentos hospitalares acrescidos dos prejuízos ligados aos anos produtivos de vida perdidos. Nesse contexto, entre 1980 e 1988, o número de mortes violentas aumentou em $67 \%$ em nosso país?

Pode-se considerar duas formas diferentes de expressão da violência: os eventos não intencionais, conhecidos como acidentes e as ações intencionais cometidas contra si mesmo ou contra terceiros (suicídios e homicídios, respectivamente). Entre as causas não intencionais, os acidentes de trânsito despontam como um grave problema de saúde pública. Os acidentes de trânsito matam 1,2 milhão de pessoas a cada ano e representam $2,3 \%$ do número total de mortes no mundo ${ }^{3}$, tratando-se, portanto, da décima causa de mortalidade mundial.

No Brasil, as estatísticas apresentadas pelo Departamento Nacional de Trânsito, do Ministério dos Transportes, demonstram que, no ano 2000, ocorreram 324.222 acidentes com vítimas, dos quais resultaram 22.102 mortes e 408.070 feridos, não havendo registro do número de ocorrências que redundaram apenas em danos materiais ${ }^{4}$.

Além do impacto das perdas humanas, de custos imensuráveis, ainda há o impacto financeiro que este tipo de acidente representa em termos de custos para 0 Estado. Baseado nas estatísticas do Instituto de Pesquisa Econômica Aplicada (IPEA), as perdas econômicas advindas dos acidentes de trânsito situam-se entre 1 e $2 \%$ do Produto Interno Bruto (PIB) nacional, algo entre $R \$ 11,67$ a 23,34 bilhões / ano (valores de 2000) ${ }^{4}$.

Os acidentes de trânsito incluem predominantemente os atropelamentos e colisões. Somente 1/3 das vítimas fatais nos acidentes de trânsito estavam embarcadas nos veículos, portanto, cerca de $2 / 3$ ocor- reu por atropelamentos ${ }^{5}$. Esses eventos chamam a atenção não só por ocorrerem em número elevado, mas também por atingirem uma população jovem, em grande parte das vezes.

0 consumo de bebidas alcoólicas pode ser apontado como um dos principais fatores responsáveis pela alta incidência dos acidentes com vítimas. De uma maneira geral, em vários países, costuma-se considerar que entre metade e um quarto dos acidentes com vítimas fatais estão associados ao uso do álcool ${ }^{6}$.

Nos Estados Unidos, segundo dados do Relatório sobre o impacto socioeconômico dos acidentes de trânsito, apresentado pelo Departamento Nacional de Trânsito, os acidentes de trânsito são responsáveis por cerca de 41.000 mortes / ano, correspondendo a prejuízos de cerca de U\$230.6 bilhões. Nesse Relatório, a influência do álcool responde por $40 \%$ de mortes, ou seja, cerca de 16.000 vítimas fatais, o que representa gastos em torno de U\$ 50 bilhões?

É interessante observar que o Relatório do IPEA não faz a devida menção ao papel da influência das bebidas alcoólicas nos acidentes de trânsito no Brasili, 9. Provavelmente, isto se deve à postura cultural, uma vez que é de conhecimento o envolvimento prevalente das vítimas com as bebidas alcoólicas. Outro aspecto de grande relevância refere-se ao fato do comprometimento da população jovem entre as vítimas fatais dos acidentes de trânsito em nosso país.

Diversas leis regulamentam 0 uso de álcool por condutores de veículos motorizados. Nas legislações de trânsito dos diferentes países, foram estipulados limites legais de alcoolemia (concentração de álcool no sangue). A alcoolemia permitida em países como Bulgária, Hungria, Polônia, Romênia e Rússia é inferior a 0,5gramas por litro de sangue $(\mathrm{g} / \mathrm{l})$. Do mesmo modo, na Austrália, Finlândia, França, Japão e Suécia, o nível de alcoolemia corresponde a 0,5g/l. Na Bélgica, Canadá, Dinamarca, Espanha, Itália e Alemanha, o nível permitido é até 0,8g/ I e nos Estados Unidos, em alguns estados é de $1,0 \mathrm{~g} / \mathrm{l}$. 0 novo Código de Trânsito Brasileiro, de 23 de setembro de 1997 (Lei n 9503), em seu artigo 276, estabelece o nível de alcoolemia limite em 0,6 g/l ou o equivalente para outras formas de medidas (bafômetro) ${ }^{10}$.

Vale ressaltar que o consumo de bebidas alcoólicas também é apontado em nosso país como um dos principais fatores causais de acidentes. Em aproximadamente $70 \%$ dos acidentes de trânsito violentos com mortes, o álcool é o principal responsável. De acordo com estatísticas do Grupo de Socorro Emergencial (GSE) 
do Corpo de Bombeiros do Rio de Janeiro, 30,9\% dos motoristas que precisaram de socorro exibiam sinais da presença de teor alcoólico no organismo ${ }^{11}$.

Por ser pouco divulgada a noção do verdadeiro teor alcoólico das bebidas é que se deve dar atenção às chamadas "bebidas leves". É importante observar que qualquer bebida contém a mesma quantidade de álcool puro por dose padrão e, ao beber um copo de $300 \mathrm{ml}$ ou uma "latinha" (350 ml) de cerveja, estaremos ingerindo a mesma quantidade de álcool puro, ou seja, em torno de 12 gramas, a mesma quantidade que há em uma taça de vinho ou dose de cachaça / uísque, alcançando a taxa de 0,2g/l (alcoolemia). Portanto, uma pessoa pode atingir $0,6 \mathrm{~g} / \mathrm{l}$ de álcool ao consumir três latas de cerveja ou três doses de uísque, variando um pouco conforme a massa corporal e a sensibilidade ao álcool do organismo ${ }^{11}$.

Ainda, a alcoolemia em torno de 0,4-0,6g/l já pode representar efetivo fator de risco ao provocar manifestações neuro-cognitivas e comportamentais em algumas pessoas a depender de certos fatores individuais ${ }^{11}$. Acima dessa taxa, 0 álcool pode promover euforia, desinibição, impulsividade, agressividade ou passividade. Tais considerações são importantes no que tange à possibilidade de riscos com níveis mais baixos do que é habitualmente permitido $(0,5 \mathrm{~g} / 1 \mathrm{de}$ sangue). 0 simples fato de coibir níveis de alcoolemia acima do permitido é insuficiente, em tese, para garantir ausência dos acidentes. Dessa forma, os resultados dependem em grande parte da maneira de implementação de programas de prevenção ${ }^{12}$.

Já em 1961, a magnitude alcançada pelos acidentes de trânsito fez com que a Organização Mundial de Saúde escolhesse como tema do ano "Acidentes e sua Prevenção", cujo objetivo era chamar a atenção dos governos e das populações para o número crescente de acidentes e sua gravidade 3 .

$E$, ainda hoje, com a insuficiência de medidas preventivas e a necessidade de uma ação pronta de combate a esse flagelo de nossos tempos, os estudos e as pesquisas sobre 0 tema são de notória importância. Principalmente ao se levar em consideração que as estatísticas disponíveis em nosso país ainda são bastante insuficientes, não demonstrando a real face da situação.

Assim, este estudo foi delineado com o seguinte objetivo: relacionar a mortalidade dos acidentes de trânsito, no período de dezembro de 2001 a fevereiro de 2002, na cidade do Rio de Janeiro, com a taxa de álcool apresentada no sangue.

\section{METODOLOGIA}

0 estudo é de natureza descritiva, com abordagem quantitativa, utilizando-se o método estatístico. Estudos com essa configuração permitem comprovar as relações dos fenômenos entre si e obter generalizações sobre sua natureza, ocorrência ou significado ${ }^{13}$.

0 referido estudo foi desenvolvido, no período de dezembro de 2001 a fevereiro de 2002, no Instituto Médico-Legal Afrânio Peixoto (IMLAP), localizado no centro da Cidade do Rio de Janeiro. Para ele são encaminhadas todas as vitimas fatais envolvidas em acidentes de trânsito, tanto por atropelamento quanto por colisão de veículos motorizados. A escolha desse período se deu em função de vários fatores, tais como final de ano, férias e carnaval, um período que predispõe a um possível aumento nas estatísticas de acidentes de trânsito na cidade do Rio de Janeiro.

A amostra foi constituída pelo universo de 2.131 prontuários, referentes a todas as mortes ocorridas no Rio de Janeiro, registradas pelo IML, no período de dezembro de 2001 a fevereiro de 2002. Desse total foram selecionadas 267 vítimas fatais de trânsito, isto é, $12 \%$ de todas as mortes ocorridas no período. Posteriormente, os prontuários referentes aos óbitos no trânsito foram analisados de acordo com um formulário previamente elaborado para servir de guia norteador. No estudo foi considerada a alcoolemia positiva quando 0 exame mostrava níveis acima de 0,6g/l de sangue, conforme determina o Código de Trânsito Brasileiro. Desse modo, a vítima que tinha alcoolemia nos intervalos abaixo de $0,6 \mathrm{~g} / \mathrm{l}$ foi considerado negativo.

A coleta de dados foi realizada pelos próprios autores, no período de junho a setembro de 2003. A autorização para a realização da mesma foi concedida pela direção do IML, sob forma de consentimento escrito que foi apresentado ao setor do arquivo, que automaticamente liberou o manuseio dos prontuários pelos pesquisadores.

A análise descritiva foi realizada através de gráficos e tabelas e a interpretação dos resultados ocorreu à luz do referencial da literatura adotada no estudo.

\section{ANÁLISE DOS RESULTADOS}

Os dados relativos à análise de 267 prontuários de vítimas fatais de acidentes de trânsito, registrados no IML do Rio de Janeiro no período do estudo, são apresentados a seguir correlacionando-os com a taxa de álcool apresentada no sangue. 
Tabela 1. Distribuição da amostra segundo a faixa etária verificada na população estudada. Rio de Janeiro, 2002.

\begin{tabular}{ccc}
\hline Faixa etária (anos): & $\mathbf{n}$ & $\%$ \\
\hline 1 a 9 & 9 & 3,4 \\
10 a 19 & 19 & 7,2 \\
20 a 29 & 49 & 18,3 \\
30 a 39 & 49 & 18,3 \\
40 a 49 & 45 & 16,9 \\
50 a 59 & 31 & 11,7 \\
60 a 69 & 30 & 11,2 \\
70 e mais & 26 & 9,7 \\
Ignorado & 9 & 3,3 \\
Total & 267 & 100,0 \\
\hline
\end{tabular}

Ao ser analisada a Tabela 1, observa-se que 0 índice de mortalidade no período do estudo estava acentuado na faixa etária de 20 a 29 anos $(18,3 \%)$ e igualmente para a faixa de 30 a 39 anos, seguido de 40 a 49 anos $(16,9 \%)$. Esses índices revelam uma população de adultos na faixa etária produtiva e participativa do mercado de trabalho, que é brutalmente retirada do contexto da sociedade como um todo.

Essa tabela também evidencia um fato marcante em relação ao impacto dessas mortes no que tange aos Anos Potenciais de Vida Perdidos (APVP), ao se observar que a mortalidade está diretamente acentuada na faixa das pessoas em idade produtiva. Nesse sentido, o Ministério da Saúde, ao analisar o indicador APVP, aponta que, por incidir com elevada freqüência no grupo de adolescentes e adultos jovens, os acidentes e violências são responsáveis pelo maior numero de APVP. E ainda acrescenta que, no Brasil, esse indicador aumentou $30 \%$ em relação a acidentes e violências, entre 1981 e 1991, enquanto que, para as causas naturais, os dados encontram-se em queda. Fica claro que, para a sociedade, é irreparável o ônus causado pela perda de pessoas em idade produtiva ${ }^{14,15}$

Ao observar a Tabela 2, verifica-se que em $67,1 \%$ da amostra não foi realizado o exame para detecção da alcoolemia, e em apenas $32,9 \%$ dos casos realizaram o exame. Isso acontece porque, apesar de ser um exame de suma importância, ele somente foi realizado nas vítimas que vieram direto da via pública, sendo esta a rotina do $\mathrm{IML}$, no momento da realização do estudo. Logo, o exame só era realizado nas vitimas fatais provenientes do hospital, até as primeiras 24 horas após a morte. Nesse caso, era feita avaliação pelo médico perito de plantão e, em seguida, prosseguido a coleta de material para análise de álcool no sangue. Já que após esse tempo vários fatores podem interferir no resultado do exame.

Tabela 2. Distribuição da amostra segundo a realização de testes de alcoolemia verificados na população estudada. Rio de Janeiro, 2002.

\begin{tabular}{ccc}
\hline Testes de alcoolemia & $\mathbf{n}$ & $\%$ \\
\hline A) Não realizados: & 179 & 67,1 \\
Realizadas & 88 & 32,9 \\
Total & 267 & 100,0 \\
B) Índice de alcoolemia: & & \\
Positivos* & 31 & 33,0 \\
Negativos & 57 & 67,0 \\
Total & $\mathbf{8 8}$ & 100,0 \\
\hline
\end{tabular}

*A partir de 0,6 g/l de sangue, utilizando-se o método de cromatografia gasosa.

A Tabela 2 ainda mostra que dos 88 registros de óbitos $(32,9 \%)$ que realizaram teste de alcoolemia, $31(33 \%)$ tiveram testes positivos (acima de $0,6 \mathrm{~g} / \mathrm{l}$ ). Porém, chamamos a atenção para os casos negati$\operatorname{vos}(67 \%)$, que foram abaixo de $0,6 \mathrm{~g} / \mathrm{l}$. Não é possível pressupor que a alcoolemia fosse zero. Por isso, seria necessário também investigar a presença de álcool no sangue com taxas menores que a permitida em nosso país, já que índices menores que 0 índice legal podem modificar significativamente 0 comportamento de quem ingere bebidas alcoólicas e dirige automóvel11, 12 .

Corroborando a análise anterior, nos EUA, a ingestão de álcool antes de dirigir é responsável por 50 a $55 \%$ dos acidentes automobilísticos fatais. Já, no Brasil, este percentual chega a $75 \%,{ }^{7,12}$. Em estudo realizado com estudantes europeus, 0 ato de não beber e dirigir e 0 uso de preservativo sexual foram apontados como as atividades mais importantes para a manutenção da saúde. No entanto, mesmo os que acreditam ser importante não dirigir após beber, admitem dirigir sob efeito do álcool ${ }^{16}$.

A Tabela 3 mostra que, ao se correlacionar as 88 vítimas de acidentes de trânsito, que realizaram 0 exame de alcoolemia, no período do estudo, observase que grande parte das vitimas (64) foi proveniente de via pública. Dessas, 27 vítimas $(42,2 \%)$ apresentaram alcoolemia positiva. Por outro lado, ao se observar 0 número de vítimas que chegaram ao IML provenientes do hospital (24) encontraram-se 20 vítimas 
Tabela 3. Distribuição da amostra segundo o resultado do exame de alcoolemia e o local do óbito. Rio de Janeiro, 2002.

\begin{tabular}{ccccccc}
\hline & & \multicolumn{4}{c}{ Alcoolemia } \\
\cline { 3 - 7 } Local dos óbitos & \multicolumn{1}{c}{ Total } & \multicolumn{2}{c}{ Negativa } & \multicolumn{2}{c}{ Positiva } \\
\hline & $n$ & $\%$ & $n$ & $\%$ & $n$ & $\%$ \\
Hospital & 24 & 100,0 & 20 & 83,4 & 4 & 16,6 \\
Via Pública & 64 & 100,0 & 37 & 57,8 & 27 & 42,2 \\
Total & $\mathbf{8 8}$ & $\mathbf{1 0 0 , 0}$ & $\mathbf{5 7}$ & $\mathbf{6 4 , 7}$ & $\mathbf{3 1}$ & $\mathbf{3 5 , 3}$ \\
\hline
\end{tabular}

$(83,4 \%)$ com alcoolemia negativa e apenas 04 vítimas $(16,6 \%)$ com alcoolemia positiva.

Ao se comparar os achados de alcoolemia positiva com óbito em via pública $(42,2 \%)$ e com os óbitos ocorridos no hospital $(16,6 \%)$, é interessante observar que a alcoolemia detectada foi mais significativa para os indivíduos que vieram de via pública e menor para os que vieram do hospital. Isso demonstra que a gravidade dos acidentes daquelas vítimas provenientes do hospital é um pouco menor que das vítimas falecidas no próprio local do acidente.

Vale salientar que, possivelmente, os índices de alcoolemia negativa encontrados, tanto em vias públicas quanto em hospital $(57,8 \%$ e $83,4 \%$, respectivamente), poderiam ser bem menores, pois eles não representavam a ausência de álcool no sangue. Por exemplo, pode-se observar casos classificados como de alcoolemia negativa, quando na verdade a taxa encontrada foi de $0,59 \mathrm{~g} / \mathrm{l}$ de sangue, uma taxa quase positiva.

Outro aspecto a ser destacado diz respeito a alguns acidentes fatais, como, por exemplo, os publicados na imprensa em 27 de junho de 2005. Um aposentado, ao estacionar seu carro, morreu ao ser atingido por uma picape em alta velocidade. Essa vítima teve morte instantânea, e quem provocou 0 acidente foi um rapaz de 23 anos. É altamente sugestivo que 0 motorista da picape estivesse alcoolizado, pois a imprensa constatou seu consumo abusivo de bebidas alcoólicas horas antes do acidente. No entanto, ele saiu com apenas alguns arranhões, foi atendido no hospital, onde não foi realizado o exame, pois 0 atendimento da emergência não inclui a alcoolemia de rotina para esses casos. Este exemplo demonstra 0 quanto nossas estatísticas não evidenciam a verdadeira realidade dos fatos.

0 álcool é um dos fatores preponderantes para desencadear e precipitar o acidente automobilístico e agravar também a intensidade das conseqüências e prejuízos. Nesse sentido, em aproximadamente 70\% dos acidentes de trânsito violentos com mortes, o álcool é o principal responsável ${ }^{11}$.

Tabela 4 - Distribuição da amostra segundo o resultado do exame de alcoolemia e a natureza do acidente. Rio de Janeiro, 2002.

\begin{tabular}{ccccccc}
\hline & & & \multicolumn{4}{c}{ Alcoolemia } \\
\cline { 3 - 7 } $\begin{array}{c}\text { Natureza } \\
\text { do acidente }\end{array}$ & \multicolumn{2}{c}{ Total } & Negativa & Positiva \\
& & & & & & \\
\cline { 2 - 7 } Atropelamento & 47 & 100,0 & 29 & 61,7 & 18 & 38,3 \\
Colisão* & 18 & 100,0 & 13 & 72,2 & 5 & 27,8 \\
Choque** & 4 & 100,0 & 3 & 75,0 & 1 & 25,0 \\
Queda de moto & 3 & 100,0 & 1 & 33,4 & 2 & 66,6 \\
Outros & 5 & 100,0 & 3 & 60,0 & 2 & 40,0 \\
Ignorado & 11 & 100,0 & 8 & 72,7 & 3 & 27,3 \\
Total & 88 & 100,0 & 57 & 64,7 & 31 & 35,3 \\
\hline
\end{tabular}

* De acordo com o Ministério dos Transportes ${ }^{4}$ entende-se por colisão, 0 acidente em que há impacto entre veículos em movimento.

**0 choque consiste-se no impacto de um veículo em movimento contra qualquer objeto fixo ${ }^{5}$.

A Tabela 4 mostra que, ao se correlacionar 0 exame de alcoolemia com a natureza do acidente, pode-se observar que 47 casos foram provenientes de atropelamentos e desses, 18 casos $(38,3 \%)$ apresentaram alcoolemia positiva. Na colisão, observa-se que, dos 18 casos $(27,8 \%)$ estavam com a alcoolemia positiva (acima de 0,6g/l). Na queda de moto, 66,6\% apresentavam também alcoolemia positiva.

Vale destacar o percentual significativo de atropelamentos das vítimas envolvidas e a presença de álcool no organismo $(38,3 \%)$. Nota-se também que, apesar da influência do álcool ser gravíssima quando combinada à direção, são os pedestres que ainda sofrem as maiores conseqüências. No Brasil, os pedestres são as maiores vítimas dos atropelamentos, diferente de demais países desenvolvidos nos quais as colisões são os tipos mais freqüentes de acidentes de trânsito ${ }^{17}$.

Acrescente-se ainda que, em emergências de três hospitais municipais do Rio de Janeiro, no período de 2000 a 2001, registraram-se um grande número de acidentes de trânsito, com um quantitativo significativo de atendimentos aos acidentados provocados por atropelamentos. Destaca-se ainda na literatura que existe uma preocupação com a maioria das vítimas de acidentes de trânsito, que morre fora dos veículos, isto é, os atropelados ${ }^{5}$. 
Nesse sentido, parece haver outros fatores sócioeconômicos e estruturais além do álcool, no que se refere às condições das vias públicas pela falta de espaço ou sinalização adequada para o pedestre. Por vezes, ele tem de andar em condições precárias, pois nas vias públicas faltam passarelas, passagens subterrâneas e calçadas para pedestres.

Tabela 5. Distribuição da amostra segundo o resultado do exame de alcoolemia e o dia da semana da ocorrência do acidente. Rio de Janeiro, 2002.

\begin{tabular}{ccccccc}
\hline & & \multicolumn{4}{c}{ Alcoolemia } \\
\cline { 3 - 7 } Dias da semana & \multicolumn{2}{c}{ Total } & \multicolumn{2}{c}{ Negativa } & \multicolumn{3}{c}{ Positiva } \\
\hline & $\mathbf{n}$ & $\%$ & $n$ & $\%$ & $n$ & $\%$ \\
\cline { 2 - 7 } Segunda-feira & 12 & 100,0 & 9 & 75,0 & 3 & 25,0 \\
Terça-feira* & 9 & 100,0 & 7 & 77,7 & 2 & 22,3 \\
Quarta-feira & 6 & 100,0 & 5 & 83,3 & 1 & 16,7 \\
Quinta-feira & 6 & 100,0 & 5 & 83,3 & 1 & 16,7 \\
Sexta-feira & 12 & 100,0 & 8 & 66,7 & 4 & 33,3 \\
Sábado & 26 & 100,0 & 13 & 50,0 & 13 & 50,0 \\
Domingo & 16 & 100,0 & 9 & 56,3 & 7 & 43,7 \\
Ignorado & 1 & 100,0 & 1 & 100,0 & - & - \\
Total & $\mathbf{8 8}$ & 100,0 & $\mathbf{5 7}$ & 64,7 & 31 & 35,3 \\
\hline
\end{tabular}

* Dias 25/12/2001 e 01/01/2002, Natal e Ano Novo respectivamente.

Como esperado, a Tabela 5 aponta que nos fins de semana, as estatísticas dos acidentes de trânsito aumentam. Observa-se 33,3\% na sexta-feira, seguido de sábado e domingo com 50,0\% e 43,7\% respectivamente. Vale ressaltar que os feriados, bem como as vésperas dos mesmos, nesse período, ocorreram nas terças-feiras referindo-se respectivamente, às festas de natal e ano novo. Este fato aumentou as estatísticas de acidentes nestes dias da semana (segundas e terças-feiras), resultando em índices de alcoolemia positiva ( $25,0 \%$ e $22,3 \%$ respectivamente).

Ao se correlacionar o nível de alcoolemia com os dias da semana, observa-se que, nas vítimas com alcoolemia positiva, encontra-se um aumento linear na positividade desses exames nos fins de semana e feriados. Tais dados confirmam o uso e abuso de álcool relacionados aos feriados e fins de semana.

Esses achados corroboraram as estatísticas apresentadas pelo GSE e DETRAN-RJ, quando apontam 0 aumento de acidentes de trânsito nos feriados e fins de semanas no Rio de Janeiro, devido ao uso e abuso de álcool pelos envolvidos (motoristas e pedestres), nos acidentes com maior gravidade ${ }^{19}$.
Outro dado que chama a atenção é que, provavelmente, os casos com alcoolemia negativa, isto é, abaixo de 0,6g// no presente estudo, em grande parte poderiam estar relacionados com pessoas que fizeram o uso do álcool de forma menos intensa ou há mais tempo antes de usarem os veículos. Contudo, eles apontam para a possibilidade de níveis de álcool no sangue abaixo de $0,6 \mathrm{~g} / \mathrm{l}$ e diferente de $0,0 \mathrm{~g} / \mathrm{l}$, podendo também representar um efetivo fator de risco.

Estudos nesse sentido precisam ser aprofundados para que se possa administrar a significância do risco relacionado ao chamado uso social do álcool, direção e acidentes. Afirma-se até que os acidentes nas madrugadas dos fins de semana são provocados pela junção dos dois maiores vilões implicados na gênese dos acidentes de trânsito, 0 álcool e a sonolência ${ }^{20}$.

Tabela 6. Distribuição dos indivíduos que apresentaram alcoolemia positiva, segundo os níveis. Rio de Janeiro, 2002.

\begin{tabular}{ccc}
\hline $\begin{array}{c}\text { Níveis de Alcoolemia } \\
\text { em } \mathbf{g} / \mathbf{l} \text { de sangue }\end{array}$ & $\mathbf{n}$ & $\%$ \\
\hline $0,6 \mid-1,0$ & 9 & 29,1 \\
$1,0 \mid-1,5$ & 10 & 32,2 \\
$1,5 \mid-2,0$ & 10 & 32,2 \\
acima de 2,0 & 2 & 6,5 \\
Total & 31 & 100,0 \\
\hline
\end{tabular}

A análise da Tabela 6 evidencia que $64,4 \%$ dos indivíduos com alcoolemia positiva apresentaram concentrações entre 1,0 e 2,0 gr de álcool / litro de sangue, 0 que é bastante preocupante, pois caracteriza o abuso do álcool. Por essa razão, os acidentes de trânsito são conseqüências conhecidas do abuso do álcool, pois é sabido que níveis a partir de $0,6 \mathrm{~g} / \mathrm{l}$ de alcoolemia provocam no cérebro alterações neuro-químicas e funcionais suficientes para mudanças de comportamento facilitadoras de situações de risco (acidentes de trânsito, domésticos, violência e homicídios) ${ }^{11}$.

Numa revisão realizada em 200 artigos científicos, a maioria mostra prejuízo das funções com alcoolemia de $0,7 \mathrm{~g} / \mathrm{l}$. E em $20 \%$ dos artigos encontrou-se perda funcional significativa em concentrações entre 0,1 e 0,4g/ 12, índice abaixo do preconizado na Lei de Trânsito. Logo, apesar de pequenas divergências nas posições encontradas, existe unanimidade ao admitir que 0 álcool e a direção estão quase sempre associados a acidentes de trânsito. Por isso, diversos países adotam limites de alcoolemia legais para os condutores de veículos. 
No Brasil, o Código de Trânsito estabelece o limite de 0,6g/l. Entretanto, alguns países já diminuíram esse limite em sua legislação, como é o caso da Suécia $(0,2 \mathrm{~g} / \mathrm{l})$ e do estado da Califórnia, nos EUA, no qual a alcoolemia aceitável para menores de 21 anos é zero ${ }^{10}$.

Contudo, apesar dos diferentes níveis de alcoolemia adotados para cada país, na nossa posição é importante destacar que os acidentes relacionados com abuso de álcool, além de mais freqüentes, são mais graves (maior taxa de morbidade) e estão ligados à ocorrência de mais vítimas fatais (mortalidade).

\section{CONSIDERAÇÕES FINAIS}

Tomando-se por base os dados obtidos neste estudo, que tem como universo um segmento de tempo limitado, porém significativo de uma realidade mais ampla, algumas considerações são necessárias no que concerne à influência do alcoolismo nos acidentes de trânsito.

A verificação da presença de álcool no sangue (alcoolemia) é uma questão da maior importância, para se mostrar o verdadeiro impacto do binômio álcool e direção. Por mais que essa combinação seja apontada como perigosa, continua-se a desconsiderar sua gravidade, mesmo quando, sob influência do álcool, os acidentes são mais graves e 0 índice de mortalidade é maior.

$\mathrm{Na}$ Tabela 3, verifica-se que o número de vítimas fatais é maior nas vias públicas e onde se constata maior freqüência de alcoolemia positiva. Tal fato decorre, naturalmente, da maior gravidade do acidente. Nesse sentido, muitas vezes, deixa-se de notificar casos fatais que ocorrem após alguns dias ou semanas de hospitalização. A perda do nexo causal uso de álcool - acidente de trânsito - morte faz com que o diagnóstico da causa mortis passe a figurar como conseqüência de alguma complicação não diretamente ligada ao acidente ocorrido. Esta é uma questão a ser considerada com a perspectiva de constatar que o número de vítimas fatais deva ser maior do que a registrada.

No que concerne à natureza dos acidentes, 0 predomínio dos atropelamentos e colisões mostra importante relação com o uso de bebidas alcoólicas. No caso de acidentes fatais com motos, também se verifica que 0 álcool tem participação evidente.

No que tange aos dias da semana, este estudo mostra os fins de semana como responsáveis pelo registro de mais de $2 / 3$ dos acidentes de trânsito, nos quais também se constata uma maior freqüência de presença do álcool. Assim, é essencial chamar a atenção para efetivas ações de combate ao abuso de bebidas alcoólicas pelos condutores de veículos nos fins de semana. Nesse estudo, surgiu uma exceção decorrente do calendário caracterizada pela alta freqüência de acidentes nas segundas e terças-feiras, quando ocorreram dois grandes feriados (natal e ano novo).

Altas taxas de alcoolemia já foram identificadas em outros estudos, e relacionadas aos acidentes de trânsito em nosso país. Neste sentido, no atual estudo, verificamos que $70 \%$ dos casos estavam com 0 nível de álcool acima de 1,0 g/l de sangue, conforme observou-se na Tabela 6.

Neste estudo, o perfil da idade das vítimas fatais mostra o predomínio da faixa etária jovem e de população economicamente ativa, correspondendo a $60 \%$ da casuística, em concordância com outros trabalhos ${ }^{14,15,16,17}$. No trabalho em pauta, a presença jovem está representada de modo acentuado, quando se considera as vítimas de até 50 anos.

Este estudo sobre a taxa de mortalidade nos acidentes de trânsito, em curto período, na cidade do Rio de Janeiro, faz parte de um trabalho de doutorado mais amplo e abrangente. Contudo, apesar dos dados levantados de forma preliminar, fica clara a influência do álcool na gravidade dos acidentes e o maior número de vítimas fatais e com seqüelas mais graves.

Estudos mais aprofundados devem ser implementados para se desenhar, com maior relevância, o verdadeiro índice do uso de bebidas alcoólicas por condutores de veículos; sobretudo os mais jovens que figuram como as maiores vítimas fatais em fins de semana.

Portanto, sendo os acidentes de trânsito influenciados pelo uso de bebidas alcoólicas, passíveis de prevenção efetiva, deve-se chamar a atenção para a necessidade de maior conscientização e responsabilização de todos os envolvidos. A finalidade deste encaminhamento seria 0 de se reduzir 0 número de vítimas fatais nos acidentes de trânsito, nos quais as bebidas alcoólicas representam um efetivo fator determinante.

É possível estabelecer ações estratégicas de prevenção desde que assumamos, como sujeitos responsáveis junto aos diversos segmentos da sociedade, o nosso papel e lembrar e usar uma simples regra bastante conhecida: se beber não dirija, se dirigir não beba. 


\section{Referências}

1. Mello Jorge MHP, Latorre MRDO. Acidentes de trânsito no Brasil: dados e tendências. Cad Saúde Pública 1994; 10( supl.1): 19-44.

2. Ferreira AN. Segurança e violência urbana. Revista de Cultura IMAE 2002; (6/7): 6-14.

3. Organização Mundial de Saúde /OMS. Os acidentes de trânsito matam 1,2 milhão de pessoas a cada ano. [on line] 2002; [ citado 03 jul 2003] Disponível em: http:// www.abramet.org

4. Ministério dos Transportes (BR). Programa Pare - Procedimentos para o tratamento de locais críticos de acidentes de trânsito. Brasília (DF); jul 2002.

5. Klein CH. Mortes de trânsito no Rio de Janeiro-Brasil. Cad Saúde Pública 1994; 10( supl.1): 168-76.

6. Pinsky I, Laranjeira R. 0 fenômeno de dirigir alcoolizado no Brasil e no mundo. Revista ABP /APAL 1998; 20 (4): 160-65.

7. Blincoe $A$, organizador. The economic impact of motor vehicle crashes-2000.USA: Department of Transportation/NHTSA Technical Report; May 2002.

8. Instituto de Pesquisa Econômica Aplicada - IPEA. Impactos sociais e econômicos dos acidentes de trânsito nas aglomerações urbanas síntese da pesquisa. Brasília(DF); maio 2003.

9. Lima JMB, Abreu AM. A violência no trânsito e uso de abuso de bebidas alcoólicas: uma grave questão de saúde pública. Info ABRAD 2004 jan/ fev/março; 2(1).

10. Carvalho DG, Leyton V. Avaliação das concentrações de álcool no ar exalado: considerações gerais. Rev Psiquiatr Clin 2000; 27.

11. Lima JMB. Alcoologia: uma visão sistêmica dos problemas relacionados ao uso e abuso do álcool. Rio de Janeiro UFRJ/EEAN; 2003.

12. Mourão LNG, organizador. A embriaguez e o trânsito: avaliação da nova lei de trânsito no que se refere à abordagem da embriaguez. Rev Psiquiatr Clin 2000; 27(2).

13. Lakatos EM, Marconi MA. Fundamentos de metodologia científica. 3a ed. São Paulo(SP): Altas; 1991.

14. Mello Jorge MHP. Violência como problema de saúde pública. Rev Sociedade Brasileira para o Progresso da Ciência 2002 jul/ago/ set; 54 (1): 52- 53 .
15. Portaria MS/GM n-737 de 16 de maio de 2001. Política nacional de redução de morbimortalidade por acidentes e violência, Brasília (DF), 2001

16. Marin L, Queiroz MS. A atualidade dos acidentes de trânsito na era de velocidade: uma visão geral. Cad Saúde Pública 2000; 16(1):7-21.

17. Minayo MCS, Souza ER, organizadores. Violência para todos. Cad Saúde Pública 1993; 9(1):65-78.

18. Abreu AMM. Morbimortalidade por acidentes de trânsito na cidade do Rio de Janeiro. Anais do 10 Encontro Alcoolismo e Saúde Pública; 2002 jul; Rio de Janeiro(RJ), Brasil. Rio de Janeiro(RJ): EEANNupenst/HESFA/CEPRAL/ NAIAT; 2002.

19. Abreu AMM, Lima JMB, Figueiró RFS. A mortalidade e morbidade por acidentes de trânsito: contribuição para 0 estudo das lesões raquimedular. Esc Anna Nery Rev Enferm 2003; 7(1): 97-103.

20. Montal JHC. No outro carro, na calçada, um ser humano. Rev Abramet 2002; 40: 35-37.

\section{Sobre as Autoras}

\section{Angela Maria Mendes Abreu}

Professora Assistente do Departamento de Enfermagem de Saúde Pública e aluna do Programa de Pós-graduação - Doutorado, da Escola de Enfermagem Anna Nery / Universidade Federal do Rio de Janeiro (UFRJ). E-mail: angelabreu@ globo.com.

\section{José Mauro Braz de Lima}

Professor Adjunto da Faculdade de Medicina e Coordenador Geral do CEPRAL da UFRJ. Doutor em Medicina. Pós-doutorado na Universidade de Paris /; Hôspital de la Salpétrière. Presidente da Sociedade Brasileira de Alcoologia.

\section{Thais de Araújo Alves}

Enfermeira Hemoterapêuta do Hematologias Associados do Rio de Janeiro e do Programa de Saúde da Família de Mesquita / Rio de Janeiro. 